\title{
Determinants of completed railway suicides by psychiatric in-patients: case-control study
}

\author{
Karoline Lukaschek, Jens Baumert, Marion Krawitz, Natalia Erazo, Hans Förstl
} and Karl-Heinz Ladwig

\section{Background}

Suicide prediction during psychiatric in-patient treatment remains an unresolved challenge.

\section{Aims \\ To identify determinants of railway suicides in individuals receiving in-patient psychiatric treatment.}

\section{Method}

The study population was drawn from patients admitted to six psychiatric hospitals in Germany during a 10-year period (1997-2006). Data from 101 railway suicide cases were compared with a control group of 101 discharged patients matched for age, gender and diagnosis.

\section{Results}

Predictors of suicide were change of therapist $(\mathrm{OR}=22.86$,
$P=0.004)$, suicidal ideation $(\mathrm{OR}=7.92, P<0.001)$, negative or unchanged therapeutic course ( $\mathrm{OR}=7.73, P<0.001)$, need of polypharmaceutical treatment $(\mathrm{OR}=2.81, P=0.04)$ and unemployment $(\mathrm{OR}=2.72, P=0.04)$. Neither restlessness nor impulsivity predicted in-patient suicide.

\section{Conclusions}

Suicidal ideation, unfavourable clinical course and the use of multiple psychotropic substances (reflecting the severity of illness) were strong determinants of railway suicides. The most salient finding was the vital impact of a change of therapist. These findings deserve integration into the clinical management of patients with serious mental disease.

\section{Declaration of interest}

None.
The suicide of an individual during in-patient treatment carries a powerful emotional charge since psychiatric in-patient care is supposed to be a safe haven from the destructive consequences of mental illness. Consequently, hospital staff often feel a sense of failure and guilt when patients who have been admitted to hospital take their own lives. Medical and nursing staff often believe that they should have assessed the patient more carefully, been more aware of hints of suicide or provided closer supervision. ${ }^{1}$ Furthermore, in the aftermath of an in-patient suicide, the staff are occupied with the containment of any further selfdestructive or suicidal behaviour among other patients in the hospital. ${ }^{2}$ Efforts have been made to identify potential risk factors in the prediction of in-patient suicides. Studies incorporating a methodologically sound case-control approach provided support for an association between in-patient suicide and previous suicidal behaviour, a history of self-harm and previous suicide attempts. ${ }^{3-10}$ Additionally, recent adverse life events, ${ }^{5-7}$ depressed mood and depression, ${ }^{3-6,10,11}$ schizophrenia, ${ }^{10}$ living alone, ${ }^{7,8,11,12}$ or being unmarried, ${ }^{11}$ were acknowledged as risk factors for in-patient suicide. Conflicting evidence exists regarding unemployment status, with two studies identifying unemployment as a risk factor for in-patient suicide, ${ }^{11,12}$ whereas another reported that people dying by suicide were less likely to be unemployed. ${ }^{6}$ During the time of hospital stay, some crucial factors deciding whether increased awareness is warranted were identified: in several casecontrol studies the highest risk was observed during the first few days after admission. ${ }^{6,7,13}$ In addition, leaving the ward without permission (absconding) was a strong predictor of in-patient suicide. ${ }^{3,6,7,14}$ Furthermore, the absence or change of a key professional can be associated with an increased risk of suicide. ${ }^{4}$

The means of suicide chosen by the patient reflects availability, ${ }^{1,15,16}$ and depends on whether the patient is on or off the ward at the time of death: suicides that occur on the ward are usually accomplished by hanging, ${ }^{17}$ whereas off-ward suicides are often more violent, including jumping off heights or in front of a moving vehicle such as a train. ${ }^{18}$ Local danger areas are generally known to experienced staff. However, it is not clear whether these hazards predispose to suicide or merely determine the method chosen. ${ }^{1}$ Railway tracks close to the facility might provide enough audiovisual stimuli to implant the idea of railway suicide in a patient's mind, especially if the tracks are easy to access. Choosing railway suicide indicates that the person is determined to end her or his life; once the decision is made, there is no room for ambiguity. ${ }^{19}$

Until now, to the best of our knowledge, no study has provided a comprehensive decision model for in-patient suicide risk, taking into account the patients' suicidal predisposition as well as events occurring after their admission to a psychiatric hospital. Thus, our study of patients drawn from several psychiatric hospitals aimed to provide a decision tree model of in-patient suicide risk probability by identifying characteristics and risk factors of patients who took their own lives ('cases') compared with patients who did not (controls). The matching criteria for controls included gender, age and admission date, but also in-patient treatment in the same facility and the primary psychiatric diagnosis. This approach ensured that any difference between cases and controls could not be the result of differences in the primary psychiatric disease. Further homogeneity was guaranteed by restricting cases to one particular means of suicide, i.e. railway suicide.

\section{Method}

The study population was drawn from all in-patients admitted to six psychiatric hospitals located in southern Germany within a 10-year period (1997 to 2006) which were in the vicinity of a place with high suicide density on the German railway network (a 'hotspot'). ${ }^{20}$ The association of railway suicide cases at these six hotspots with nearby psychiatric hospitals was examined by comparing missing persons and suicide cases with the National Central Registry of all personal accidents on the German railways. 
This registry documents all personal accidents on the entire German railway track system except for municipal subway providers. From this registry all fatal suicide cases satisfying the operational definition of an act of suicidal behaviour according to the ICD-10 category 'intentional self-harm by jumping or lying in front of a moving object' (code X81) were identified. ${ }^{21}$ Fatal suicide was defined as 'death within 30 days'. A case-control study was carried out with patient data (suicide group $n=101$, matched control group $n=101$ ) from these six psychiatric hospitals. Suicide cases were defined as railway suicide between 1997 and 2006 by a person receiving in-patient treatment in a mental health ward in one of the six psychiatric hospitals. By definition, the ward had to be close $(\leqslant 2 \mathrm{~km})$ to tracks of the German railway company Deutsche Bahn. Each suicide case was then matched with an in-patient control according to the following five criteria (in descending order of importance): in-patient treatment in the same facility; gender; primary psychiatric diagnosis on admission according to ICD-10 coding; age; and admission date. The study was approved by the ethics committee of the Technische Universität München.

Patient data were obtained retrospectively by reviewing hospital records at each facility using a specially designed report form that provides assistance in the evaluation of suicidal patients in an in- or out-patient setting. ${ }^{22}$ This form comprised 54 items: 8 sociodemographic variables (age, gender, family status, living alone, place of residence, religion, children, employment status); 14 items related to clinical data, including legal basis of admission, psychiatric diagnosis at time of admission, seasonal variation in the severity of the disorder, addictions, physical diagnosis at time of admission, duration of the psychiatric disorder, number of previous admissions, out-patient treatment, psychosocial triggers, suicidality at the time of admission, previous suicide attempts and family history of suicide; 14 items related to therapy and treatment details, including change of diagnosis during treatment, new diagnosis, treatment setting, permission to leave, medication, compliance, change of medication in the past week, duration of in-patient treatment, therapeutic course, having been scheduled for discharge and time until discharge; 9 items regarding psychopathological status at admission and during treatment; and 9 items related to suicidal behaviour (suicidal ideation during the course of treatment, indication of a current crisis, warning signs, suicide note, place, method, date, time and witnesses of the suicide). The physicians in charge were registrars and boardcertified psychiatrists who saw their psychiatric in-patients at least briefly every day and offered longer sessions once or twice a week, or even more frequently in times of crises.

\section{Assessment of medication}

For the cases group medication at the time of the suicide was reported. Additionally, adjustments or changes in medication within the 2 weeks prior to suicide were documented. For the control group no information about medication after discharge was available; therefore, medication at the time of discharge was chosen for the assessment of this variable. Additionally, any adjustment or change in medication within 2 weeks prior to discharge was documented. Medication specified in the hospital charts included tricyclic antidepressants (TCAs), selective serotonin reuptake inhibitors (SSRIs), other antidepressants, lithium, neuroleptics and benzodiazepines. Polypharmaceutical treatment was defined as being prescribed three or more drugs.

\section{Statistical analysis}

Descriptive analyses were performed using the $\chi^{2}$ test or Fisher's exact test for categorical variables; in case of group differences for continuous variables, $t$-tests or Mann-Whitney $U$-tests were used. Potential modifications of these associations by gender were assessed by basic logistic regression including the respective interaction terms in the regression equation. For multivariate analyses, logistic regression was performed to identify potential determinants for the occurrence of in-patient suicide using a stepwise variable selection. ${ }^{23}$ For the variable selection procedure, an entry criterion of a probability value $P<0.25$ in the univariate analyses and a stay criterion of $P<0.05$ in the end model were chosen. The area under the curve (AUC) and the HosmerLemeshow statistic were used to assess the model fit. ${ }^{23}$ In some cases, information on the parameter in question was not documented in the patient file and was therefore labelled 'unknown' in the questionnaire. Unknown parameters were treated as missing values and were included in the logistic regression as own category. In total, three models were calculated including the following variables based on the entry criterion described above. The first model, which assessed the patients' predispositions, included the variables living arrangements, employment status, compulsory admission order, duration of psychological illness until admission, suicidality at admission, previous suicide attempts and family history of suicide. The second model assessed the following post-admission events during hospital stay: polypharmaceutical treatment, change of therapist, therapeutic course, suicidal ideation and number of psychopathological symptoms. The third model was calculated using stepwise variable selection and included all the variables from the first and second models. Additionally, to identify subgroups with low or high suicide frequency, we performed a classification and regression tree (CART) analysis as described by Breiman et al, ${ }^{24}$ including all variables of the final model in a complete data-set $(n=140)$. A CART analysis is a tree-based approach with a sequence of tests to assess a significant difference in a response variable (e.g. suicide frequency) by an explanatory variable (e.g. sociodemographic, clinical and psychopathological variables). In each step, the explanatory variable with the lowest $P$ value drawn from the test is chosen to be the node. This multivariate procedure allows the identification of different subclasses of the study population with respect to an outcome variable. With the minimum $P$ value approach the study population is divided into subsequent different dichotomous subclasses (nodes). If no further significant association is observed for the patients in a node or the number of patients in a node is below $20 \%$ of the sample size $(n=28)$, the partition procedure stops for this node which is then labelled a 'terminal' node.

A value of $P<0.05$ was considered to be statistically significant. All evaluations were performed with the statistical software package SAS version 9.2 for Windows except the CART analysis which was done using $\mathrm{R}$ version 2.8.1. The analysis and description in this article follow the Strengthening the Reporting of Observational Studies in Epidemiology (STROBE) guidelines for case-control studies. $^{25}$

\section{Results}

The study population $(n=202)$ was predominantly male $(63.4 \%)$. The mean age was 40.3 years (s.d. $=14.4$, range $17-90)$. The main diagnoses leading to admission were schizophrenia (62.4\%), affective disorders (26.2\%), behavioural disorders due to psychotropic substance misuse (5.5\%), personality or behavioural disorders (4.5\%) and neurotic or somatoform disorders (1.0\%).

\section{Demographic characteristics}

Table 1 displays the main sociodemographic characteristics of participants in the cases and control groups that were not 


\begin{tabular}{|c|c|c|c|c|}
\hline & $n$ & Cases & Controls & $P$ \\
\hline \multicolumn{5}{|l|}{ Sociodemographic factors, $n$ (\%) } \\
\hline Employment status & 184 & & & 0.01 \\
\hline Retired & & $32(33)$ & $13(15)$ & \\
\hline Unemployed & & 34 (35) & 31 (36) & \\
\hline Employed $^{a}$ & & $32(33)$ & $42(49)$ & \\
\hline Living arrangement & 195 & & & 0.18 \\
\hline Living alone & & $36(37)$ & $27(28)$ & \\
\hline Not living alone & & $62(63)$ & 70 (72) & \\
\hline Marital status & 196 & & & 0.27 \\
\hline Married & & $32(32)$ & $38(40)$ & \\
\hline Separated, divorced, widowed & & $68(68)$ & $58(60)$ & \\
\hline Parenthood & 195 & $32(33)$ & $38(39)$ & 0.34 \\
\hline \multicolumn{5}{|l|}{ Clinical information } \\
\hline Duration of mental illness until admission, years: $n(\%)$ & 184 & & & 0.047 \\
\hline$\leqslant 1$ & & $28(28)$ & $19(22)$ & \\
\hline $1-4$ & & $10(10)$ & $20(24)$ & \\
\hline$>4$ & & $61(62)$ & $46(54)$ & \\
\hline Compulsory admission, $n$ (\%) & 200 & $20(20)$ & $29(29)$ & 0.16 \\
\hline Number of previous psychiatric admissions: median (min/max) & 192 & $3(0 / 83)$ & $2(0 / 43)$ & $0.62^{b}$ \\
\hline \multicolumn{5}{|l|}{ Suicidal behaviour, $n$ (\%) } \\
\hline Previous suicide attempt & 184 & $46(50)$ & $25(27)$ & 0.002 \\
\hline Family history of suicide & 133 & $10(15)$ & $4(6)$ & 0.11 \\
\hline Suicidality at admission & 196 & 35 (35) & $23(24)$ & 0.074 \\
\hline Substance misuse, $n$ (\%) & 190 & $29(30)$ & $28(30)$ & 0.97 \\
\hline
\end{tabular}

controlled by matching criteria. Despite being matched for age, significantly more people in the cases group than in the control group were retired or unemployed $(P=0.01)$. No statistically significant difference between the two groups regarding living arrangements, marital status or parenthood was observed.

\section{Suicidal behaviour and clinical information on admission}

Suicide attempts before admission were more prominent among the cases group compared with controls (Table 1). Significantly more patients in the cases group had at least one previous suicide attempt $(P=0.002)$ and suicidality was also higher. Regarding the duration of mental illness, patients in the cases group had been admitted either sooner (within 1 year after onset) or much later (more than 4 years after onset) than controls $(P=0.047)$. No statistically significant difference between cases and controls could be detected regarding previous psychiatric admission, duration of illness, admission by compulsory admission order or substance misuse. Although a family history of suicide was more prominent in the cases group, the difference between the groups was not statistically significant $(P=0.11)$.

\section{Medication at index event}

The medication of patients at the time of the index event (suicide for cases, discharge for controls) is given in Table 2. Overall, the intensity of pharmacological therapy was higher in the cases group, with SSRI and benzodiazepine use differing significantly from the control group $(P=0.01$ and $P=0.002$ respectively). Medication with lithium was rare and was insignificantly more common in the control group. More than a third (38\%) of patients in the suicide group were receiving polypharmaceutical treatment compared with $16 \%$ of the control group $(P<0.001)$. Additionally, we examined whether any modification in the pharmacological treatment occurred during the 2 weeks prior to the index event. The data indicate that the disease status of cases required extensive treatment modification $(P=0.005)$. Table 2 shows in detail which modifications were made to the medication of patients in the two groups. Differences were observed regarding the initiation of antidepressant therapy $(P=0.014)$ and adjustments of SSRI dosage $(P=0.007)$. A closer look at patients taking SSRI medication $(n=31)$ revealed that suicide was completed by $71 \%$ $(n=22)$ and that significantly more of those in the cases group (73\%, $n=16)$ additionally took benzodiazepines $(P=0.017)$. Patients in the cases group taking SSRI medication were more likely to have had an increase in symptom severity (three or more psychopathological symptoms) during their hospital stay than the control group ( $45 \%$ v. $22 \%, P=0.42)$.

\section{Treatment and therapeutic setting}

The therapeutic setting during the hospital stay turned out to have a major impact on suicide risk (Table 2). A change of therapist in the week prior to suicide was experienced by a fifth of the cases group, leading to a statistically significant difference between the groups $(P<0.001)$. Furthermore, patient records revealed signs of suicidal ideation among the cases group $(P<0.0001)$. As a consequence, the therapeutic course was rated as unchanged or negative for almost a third (31\%) of the cases group, but for only $12 \%$ of the control group $(P=0.001)$. In $21 \%$ of suicide cases an acute crisis was documented shortly before the suicide.

\section{Arrangements at the time of suicide}

Most of the 101 suicides occurred within the first 3 months of admission: $9 \%$ occurred within the very first week, $37 \%$ within the first 4 weeks, $27 \%(n=27)$ within the second month and $15 \%(n=15)$ within the third month. A total of 30 cases $(30 \%)$ were designated for discharge from hospital, whereas in 63 cases (62\%) treatment was to be continued; in 8 cases $(8 \%)$ this information was missing. The majority of patients who later died by suicide on the railway tracks had been assigned to an open ward at the time of death $(82 \%)$ and were allowed to leave the 


\begin{tabular}{|c|c|c|c|}
\hline & $\begin{array}{c}\text { Cases } \\
n(\%)\end{array}$ & $\begin{array}{c}\text { Controls } \\
n(\%)\end{array}$ & $P$ \\
\hline \multicolumn{4}{|l|}{ Medication at index event $(n=202)$} \\
\hline TCA, stimulating & $1(1)$ & $2(2)$ & 1 \\
\hline TCA, sedating & $17(17)$ & $11(11)$ & 0.22 \\
\hline SSRI & $22(22)$ & $9(9)$ & 0.01 \\
\hline Other antidepressant & $15(15)$ & $14(14)$ & 0.84 \\
\hline Lithium & $4(4)$ & $9(8)$ & 0.15 \\
\hline Neuroleptics, sedating & $43(43)$ & $31(32)$ & 0.08 \\
\hline Neuroleptics, extrapyramidal side-effects & $32(32)$ & $21(21)$ & 0.08 \\
\hline Neuroleptics, atypical & $43(43)$ & $49(48)$ & 0.40 \\
\hline Benzodiazepines & $41(41)$ & $21(21)$ & 0.002 \\
\hline Polypharmaceutical treatment & $38(38)$ & $16(16)$ & $<0.01$ \\
\hline \multicolumn{4}{|c|}{ Modification of medication $\geqslant 2$ weeks before index event $(n=175)$} \\
\hline Initiation of antidepressant therapy & $7(7)$ & $0(0)$ & 0.014 \\
\hline Adjustment of SSRIS & $8(8)$ & $0(0)$ & 0.007 \\
\hline Discontinuation of antidepressants & $3(3)$ & $3(3)$ & 1 \\
\hline Initiation of neuroleptic therapy & $3(3)$ & $3(4)$ & 1 \\
\hline Adjustment of neuroleptics & $21(22)$ & $11(13)$ & 0.07 \\
\hline Discontinuation of neuroleptics & $0(0)$ & $1(1)$ & 0.49 \\
\hline Initiation of benzodiazepines & $5(5)$ & $2(34)$ & 0.44 \\
\hline Discontinuation of benzodiazepines & $7(7)$ & $4(5)$ & 0.38 \\
\hline \multicolumn{4}{|c|}{ Therapeutic setting during hospital stay and treatment progression } \\
\hline Change of therapist $(n=175)$ & $20(22)$ & $3(3)$ & $<0.001$ \\
\hline Therapeutic course $(n=197)$ & & & 0.001 \\
\hline Positive & 68 (69) & $86(88)$ & \\
\hline Unchanged or negative & $31(31)$ & $12(12)$ & \\
\hline Suicidal ideation $(n=167)$ & $37(37)$ & $6(9)$ & $<0.001$ \\
\hline
\end{tabular}

ward $(80 \%)$. A minority of suicides took place after the patient had absconded from hospital (5\%). An acute crisis was documented in $21 \%$ : of these, $2(9 \%)$ were assigned to a secure ward and $3(14 \%)$ had permission to go out with an accompanying person. Nine patients (9\%) gave an early concrete warning; of these, 2 had restricted permission to go out and 1 was detained on a secure ward. Only $6(6 \%)$ left a suicide note.

\section{Psychopathological symptoms}

Of the symptoms that first occurred during hospital stay, sustained depressive mood was significantly associated with in-patient suicide $(P=0.005$; Table 3$)$. Patients in the control group $(19 \%)$ were slightly more impulsive than those in the cases group $(12 \% ; P=0.17)$, whereas restlessness and increased drive were more prevalent among the control group $(P=0.19)$. Patients in the cases group more often reported three or more psychopathological symptoms than did those in the control group $(P=0.001$, Table 3$)$. Self-harm was observed in more cases group patients, but the difference was not significant $(P=0.21)$.

\section{Gender differences}

Interaction analyses revealed that the associations described above were not modified by gender, indicating a stable pattern of suicide risk in both men and women in this study population.

\section{Multivariate analyses}

Logistic regression analyses

To identify potential risk factors for in-patient suicide, logistic regression models focused first on suicidal predisposition, second on events after admission, and finally the strength of association of all factors in a combined model (Table 4). Regarding in-patients' suicidal predisposition (first model), being retired $(\mathrm{OR}=3.87$, 95\% CI 1.60-9.32, $\quad P=0.003)$, previous suicide attempts (OR $=3.05,95 \%$ CI 1.53-6.07, $P=0.002)$ and duration of mental illness ( $\leqslant 1$ year, $\mathrm{OR}=4.21,95 \% \mathrm{CI} 1.49-11.88, P=0.007 ;>4$ years, $\mathrm{OR}=2.53,95 \%$ CI $1.00-6.38, P=0.049)$ significantly increased the suicide risk compared with their respective reference groups. Differences between unemployed and employed patients failed to reach statistical significance $(\mathrm{OR}=2.08,95 \%$ CI $0.98-4.41$, $P=0.056$ ). Living arrangements, compulsory admission order, duration of mental illness until admission, suicidality at admission and family history of suicide had no impact on subsequent suicide. With regard to the model fit, an AUC of 0.76 was estimated, showing a sufficient ability of risk prediction. The Hosmer-Lemeshow statistic indicated an excellent model fit $(P=0.84)$.

Regarding post-admission events (second model), the strongest effect on suicide risk was observed for patients with a change of therapist, indicated by an almost 19-fold risk increase $(P=0.006)$. A therapeutic course rated as 'unchanged' or 'negative' increased the suicide risk about 8.5 times $(P<0.001)$. Suicidal ideation during hospital stay was significantly associated with the risk of in-patient suicide $(\mathrm{OR}=7.35, P<0.001)$. Regarding the impact of medication, treatment with three or more different drugs significantly increased the risk of suicide $(\mathrm{OR}=2.90$, $P=0.023$ ). An AUC of 0.88 was estimated showing a sufficient ability to predict risk prediction, and the Hosmer-Lemeshow statistic indicated an excellent model fit $(P=0.46)$.

In the final model combining in-patient predispositions at baseline and post-admission events (data not shown), unemployment ( $\mathrm{OR}=2.72, P=0.04)$ was the only baseline risk factor to remain in the model, whereas retirement only just did not reach significance $(P=0.051)$. From the post-admission model, all factors (change of therapist: $\mathrm{OR}=22.86, P=0.004$; suicidal ideation: $\mathrm{OR}=7.92$, $P<0.001$; negative or unchanged therapeutic course: $\mathrm{OR}=7.73$, 


\begin{tabular}{|c|c|c|c|}
\hline & $\begin{array}{c}\text { Cases } \\
n(\%)\end{array}$ & $\begin{array}{c}\text { Controls } \\
n(\%)\end{array}$ & $P$ \\
\hline \multicolumn{4}{|l|}{ Symptom } \\
\hline Affective flattening & $26(26)$ & $16(16)$ & 0.08 \\
\hline Depressed mood & $67(66)$ & $47(46)$ & 0.005 \\
\hline Euphoria & $4(4)$ & $5(5)$ & 0.73 \\
\hline Guilt/failure & $13(13)$ & $6(6)$ & 0.09 \\
\hline Impulsivity & $12(12)$ & $19(19)$ & 0.17 \\
\hline Morning low & $6(6)$ & $7(7)$ & 0.77 \\
\hline Numbness & $6(6)$ & $4(4)$ & 0.52 \\
\hline Resignation & $17(17)$ & $10(10)$ & 0.15 \\
\hline Restlessness $^{a}$ & $36(36)$ & $27(27)$ & 0.19 \\
\hline Worthlessness $^{a}$ & $12(12)$ & $9(9)$ & 0.50 \\
\hline Number of psychopathological symptoms ${ }^{b}$ & & & 0.001 \\
\hline$\leqslant 2$ & 70 (69) & $87(88)$ & \\
\hline$\geqslant 3$ & 31 (31) & $12(12)$ & \\
\hline Self-harm ${ }^{c}$ & $13(13)$ & $8(8)$ & 0.21 \\
\hline
\end{tabular}

\section{Table 4 Association of determinants and suicide risk estimated by logistic regression models ${ }^{\mathrm{a}}$}

\section{$\mathrm{OR}(95 \% \mathrm{Cl})$}

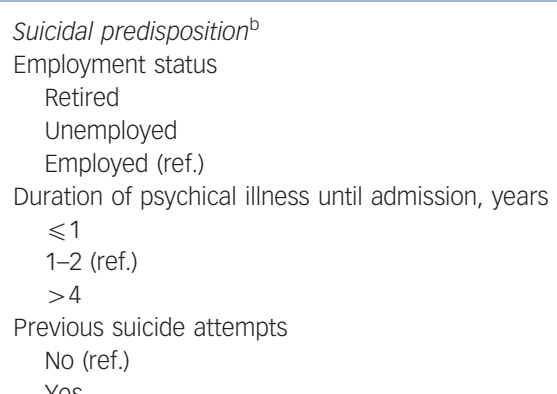

Yes

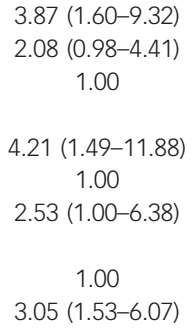

Post-admission events ${ }^{c}$

Change of therapist

$\begin{array}{lr}\text { No (ref.) } & 1.00\end{array}$

Yes
Therapeutic course

Positive (ref.)

Unchanged or negative

$18.87(2.32-153.72)$

suicidal ideation

No (ref.)

Yes

Polypharmaceutical treatment No (ref.)

Yes

$8.57(2.64-27.80)$

1.00

7.35 (2.66-20.30)

1.00

$2.90(1.16-7.28)$

\section{$P$}

AUC $=0.76$, HL statistic $4.21, P=0.84$

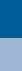

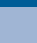

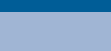

AUC $=0.88$, HL statistic $5.65, P=0.46$

AUC, area under the curve; HL, Hosmer-Lemeshow; ref., reference.

a. Missing values were included as a category; estimates are not shown.

b. Selected variables for model 1 (patients' predisposition): living arrangements, employment status, compulsory admission order, duration of psychical illness until admission

in years, suicidality at admission, previous suicide attempts, family history of suicide.

c. Selected variables for model 2 (post-admission events): polypharmaceutical treatment, change of therapist, therapeutic course, suicidal ideation, number of psychopathological symptoms.

$P<0.001$; polypharmaceutical treatment: $\mathrm{OR}=2.81, P=0.04)$ were retained in the model. Thus, one can conclude that the characteristics at admission lost their significant impact on suicide mortality when post-admission conditions were taken into account. Regarding model fit, an AUC of 0.90 was estimated showing an excellent ability of risk prediction, and the Hosmer-Lemeshow statistic indicated an excellent fit $(P=0.62)$.

A sensitivity analysis was performed by repeating the logistic regression analysis in a complete data-set, i.e. without missing values for any of the variables in the end model ( $n=140$ with 86 cases and 54 controls). When comparing estimates from the full data-set $(n=202)$ with estimates from this complete data-set the odds ratios were similar (change of therapist $\mathrm{OR}=21.59$, $P=0.005$; suicidal ideation $\mathrm{OR}=8.06, P<0.001$; negative or unchanged therapeutic course $\mathrm{OR}=6.35, \quad P=0.003$; polypharmaceutical treatment $\mathrm{OR}=2.65, P=0.06$; unemployment $\mathrm{OR}=2.43, P=0.11$ ); the percentage change in odds ratios ranged from $-2 \%$ to $18 \%$. The model fit in the complete data-set was 


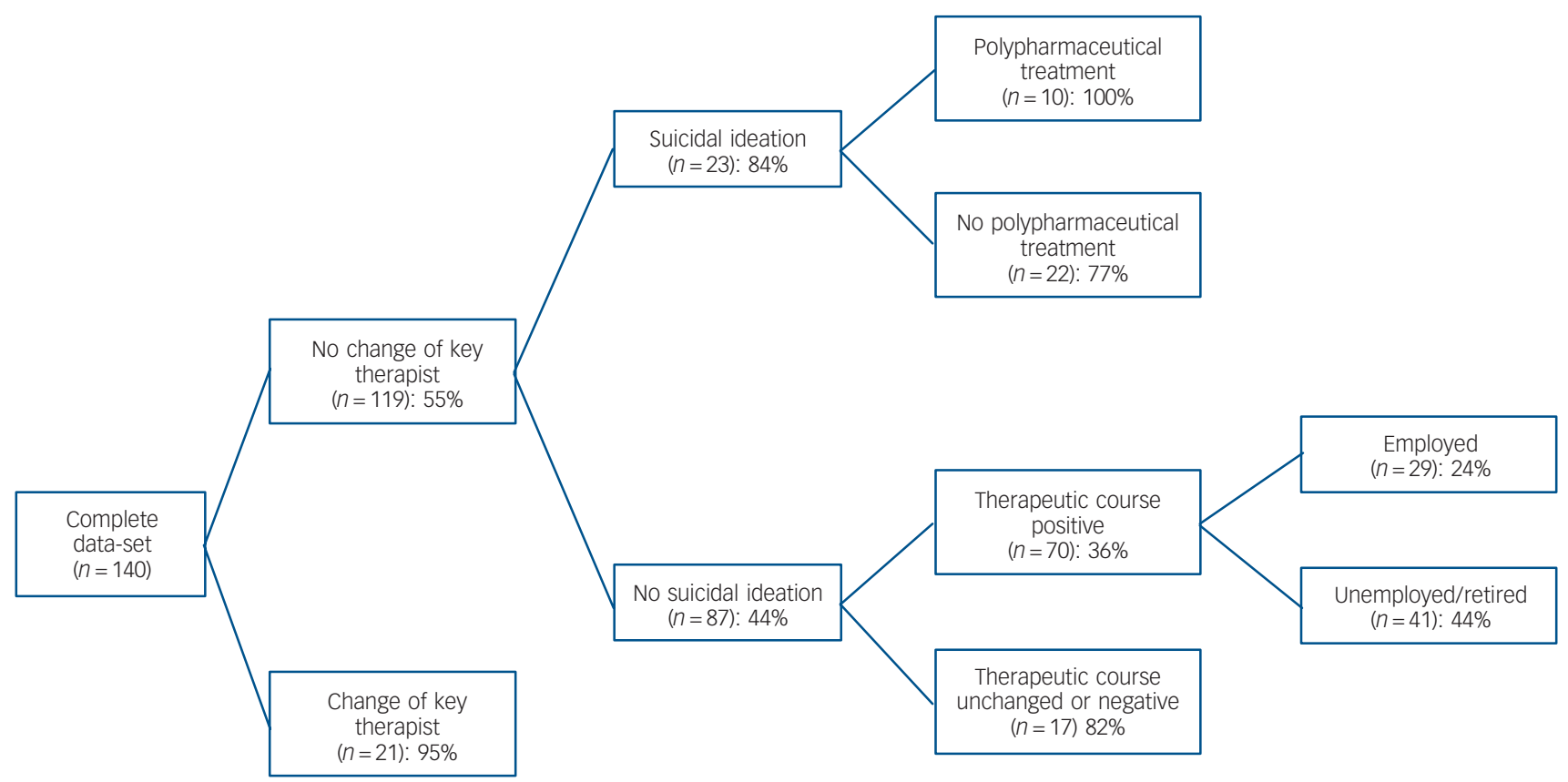

Fig. 1 Classification and regression tree analysis showing subgroups with low or high suicide probability.

excellent with an AUC of 0.83 and a Hosmer-Lemeshow statistic of $7.75(P=0.36)$.

\section{CART analysis}

In order to identify subgroups at high risk of suicide a CART analysis was carried out in the subsample of 140 patients with complete data (Fig. 1). This analysis assessed the variables included in the final model (change of therapist, suicidal ideation, therapeutic progression, polypharmaceutical treatment and employment status) and revealed six terminal nodes with suicide probabilities in subgroups ranging from $24 \%$ to $100 \%$. The lowest number of suicides was found within the subgroup who did not experience a change in therapist, showed no suicidal ideation during hospital stay, were positively rated regarding the therapeutic progression and were employed $(24 \%, n=29)$. The highest suicide risk (95\%) was found for the subgroup that experienced a change in therapist. Among those who did not experience a change in therapist, suicide risk was highest for those who showed signs of suicidal ideation and were subjected to polypharmaceutical treatment $(100 \%)$; the risk was next highest $(82 \%)$ for those who showed no suicidal ideation but whose therapeutic progression was rated as unchanged or negative.

\section{Discussion}

We analysed individual risk at admission and factors during the hospital stay in a comprehensive case-control approach in order to identify risk factors for in-patient suicide. The strongest effect was observed for patients whose key therapist had changed, which resulted in a more than 20 -fold increase in suicide risk in the final multivariate analysis. The loss of a confidant is a disturbing event that can trigger suicide in vulnerable patients and therefore must be met with increased attention by hospital staff. ${ }^{4}$ Furthermore, a therapeutic course that was rated 'unchanged' or 'negative' significantly increased the suicide risk. It has been reported that suicide risk may increase when the therapeutic alliance breaks down and the patient shows recurrent relapses and resistance to treatment. ${ }^{26}$ Another strong association was observed for suicidal ideation during the hospital stay, resulting in a 7 -fold increased risk of in-patient suicide. A recent review confirmed a positive association of suicidal ideation while in hospital and subsequent suicide. ${ }^{10}$ It is noteworthy that in a study by Busch et al the majority of in-patients for whom information on suicidal ideation was available denied suicidal thoughts and intent at their last communication before suicide. ${ }^{27}$ Regarding the new onset of psychopathological symptoms during the hospital stay (independent from the admission diagnosis), significantly more patients in the cases group experienced more than two symptoms. A significant difference between cases and controls was detected for depressive mood in the univariate model, but it did not reach significance in our multivariate model. Contrary to previous studies pointing to an association between impulsivity and suicidal behaviour, ${ }^{28}$ impulsivity was more prominent in our control group, although the difference did not reach significance.

The relationship of pharmacotherapy and in-patient suicide is difficult to determine and results vary between studies. ${ }^{29}$ Overall, our study revealed that polypharmaceutical treatment was significantly more common among cases than controls. One can conclude that symptom severity was increasing among the suicide group, leading to a devastated state of mind which in turn resulted in more medication to counteract the severity of illness. In our study a statistically significant association between the intake of SSRI and the risk of suicide was observed. Further analysis of a subgroup of patients receiving SSRI treatment revealed an increased risk for patients additionally taking benzodiazepines and with a multitude of psychopathological symptoms. The SSRIs may have contributed to an increase in drive and unstable mood during critical treatment periods in some patients, ${ }^{9}$ thereby increasing the risk of suicide. On the other hand, antidepressant treatment might have been initiated because the patient had entered an acute depressive phase; hence, the suicide was due to the depressive mood rather than the medication. Depressive mood has been frequently considered as a predictor of suicidal behaviour. ${ }^{15,29}$ Notably, a recent review observed a tendency for decreasing suicide rates in European countries where the use of 
antidepressants, including SSRIs, has been increasing. ${ }^{30}$ Given the evidence above, one can conclude that patients in the suicide group had been steadily deteriorating (sustained depressive mood, negative healing progression, suicidal ideation), their condition additionally weakened by the loss of a confidant (change of therapist). The hospital staff evidently tried to break this downward development by increasing the pharmaceutical treatment.

The results from the multivariate regression model were also corroborated by the CART analysis. The study population could be divided in several subgroups. The main divisors were change in therapist, therapeutic progress and suicidal ideation.

Compared with events during the hospital stay, patients' predispositions at admission lost their significant impact on suicide mortality when post-admission conditions were taken into account in a combined model. Nonetheless, staff should pay attention at admission to individual characteristics that emerged as potential risk factors for in-patient suicide in our analysis. As generally acknowledged, ${ }^{10,31,32}$ previous suicide attempts were a strong predictor of later suicide. We also found that short illness ( $<12$ months) was predictive of suicide, probably due to more severe symptoms among these patients. Long illness ( $>4$ years) barely achieved significance, possibly reflecting an enduring struggle with illness. Our study identified retirement or unemployment as risk factors for suicide. This finding is important, because although cases and controls were matched for age, significantly more of those in the cases group were not among the working population. Unemployment is strongly related to increased suicide mortality. ${ }^{28,33,34}$ This may be due to the rapid social changes and sense of alienation that can occur when a person becomes unemployed or is made redundant. Expecting a lower standard of living after losing a job leads to higher suicide mortality. ${ }^{35}$ This result may be explained by the stress-related consequences of experiencing uncertainty. A multilevel analysis of self-perceived job insecurity in 17 European countries revealed that it has far-reaching negative effects on physical and mental health. ${ }^{36}$ Unemployment, a state of seeking and currently lacking an established social position in life, is itself stressful and stigmatising. Additionally, being deprived of work makes the individual more psychologically vulnerable to other adversities, and increases the risk of isolation. ${ }^{35}$ Job loss tends to precede the onset of psychiatric disorders and is associated with clinical and subclinical depression, anxiety, substance and alcohol misuse and antisocial behaviour. ${ }^{37}$ The frustration of becoming unemployed and the lack of a job are factors that affect human levels of aggression and autoaggression, and provoke emotional states conducive to suicidal behaviour. Notably, a family history of suicide did not emerge as a risk factor, although it was present more often among cases than among controls. However, findings on family history of suicide are highly incongruent. ${ }^{10,15}$

\section{Characteristics of in-patient suicide}

In our study a third of suicides occurred within the first month after admission. The first weeks after admission are generally acknowledged to be a high-risk period for in-patient suicide. ${ }^{3,13,15,26,29,32,38}$ The majority of suicides took place when the patients were on agreed leave. Knowing that the first weeks of hospitalisation are a time of increased vulnerability, careful assessment of patients who have been given permission to leave might also reduce in-patient suicides. It is noteworthy that in only a small proportion of cases were warning signs observed, which complicates the early detection of suicidal intention. ${ }^{27}$ In several hospitals that we investigated a clustering of railway suicides occurred within a short period: from the data we cannot deduce whether the patients who died knew each other, or to what extent details about the incidents circulated among patients. Research evidence for in-patient suicide clustering and contagion is poor. ${ }^{15}$ However, as suggested above, railway tracks located close to the facility might provide enough audiovisual stimuli to implant the idea of railway suicide in a patient's mind. This hypothesis has been investigated in a number of studies, which yielded ambiguous results. ${ }^{39}$ Studies of railway suicides in Belgium concluded that the existence of a medical institution in the vicinity of a railway track was a defining characteristic of hotspots. ${ }^{40,41}$ In Australia also, sections of railway lines in the vicinity of mental health facilities have been identified as hotspots. ${ }^{42}$ On the other hand, Symonds showed that psychiatric in-patients did not select the station or railway line closest to their unit, but instead chose a location closer to their home. ${ }^{43}$ Almost two-thirds of the study sample were admitted with schizophrenia as their primary diagnosis upon admission. This provides further evidence for the hypothesis that railway suicide is typical of patients experiencing schizophrenic psychosis. ${ }^{44}$

\section{Measures to prevent railway suicide}

Although railway suicides represent only a small proportion of all suicides, ${ }^{45,46}$ they cause the majority $(>60 \%)$ of fatalities on railways in the EU. ${ }^{47}$ Owing to the immense human and economic cost of such suicides, innovative preventive measures are warranted. Initial evidence has suggested that technical measures such as restricting access (e.g. by installing physical barriers in strategic places), ${ }^{41,48}$ or the installation of blue lights on train platforms, as in Japan, ${ }^{49}$ are effective. Non-technical approaches, such as awareness programmes or gatekeeper training courses, have also shown promise. ${ }^{50,51}$ An integral part of such courses is to train people to recognise the behavioural patterns of those possibly contemplating railway suicide, ${ }^{52,53}$ and to be alert for specific high-risk time windows of this form of suicide (e.g. weekdays, daytime). ${ }^{54}$ In Germany an array of preventive measures was implemented in 2002 within the framework of the German Railway Suicide Prevention Project. It included an awareness programme, media approaches and hotspot analysis, ${ }^{20}$ as well as the introduction of a rule regarding passenger announcements requiring avoidance of the term 'suicide.. ${ }^{19}$ This selection of measures led to a decline in railway suicides.

\section{Strength and limitations}

Strengths of the study include its case-control design and the thorough and exhaustive review of charts. Matching cases and controls for their primary admission diagnosis ensured that differences between the groups could not be a result of differences in the primary psychiatric disease. Few case-control studies have matched participants for the main diagnosis, ${ }^{3,4,31}$ and the numerator/denominator problem has therefore not been addressed in many studies, leading to an overrepresentation of suicide cases with a diagnosis of bipolar disorder or schizophrenia. A limitation of our study was the inclusion solely of patients who took their own lives during a hospital stay; the study did not include people who took their own lives shortly after being discharged, a situation known for its high suicide risk. ${ }^{55-57}$ It cannot be completely ruled out that the retrospective approach introduced bias, although it is unlikely: entries to the hospital records were made before patients were discharged or died. The number of patients in some subgroups was small, leading to wide confidence intervals. Differences in the mental healthcare systems between countries may limit generalisability. Our sample was restricted to railway suicides in particular in order to provide 
further knowledge about the clinical risk factors for in-patients choosing this form of suicide.

\section{Implications}

Understanding the factors associated with an increased likelihood of suicide has the potential to save lives. The findings of this case-control study confirm the need for a thorough anamnesis of in-patients' medical history: patients presenting at psychiatric centres should be specifically questioned about their employment status and previous suicide attempts. The most salient finding of our study was the vital impact of a change of therapist for highrisk patients. Among those who did not experience a change in therapist, suicide risk was highest for those who showed signs of suicidal ideation and were subjected to polypharmaceutical treatment. If no suicidal ideation was reported, an unchanged or negative therapeutic progression led to an increased risk. A short duration ( $<12$ months) of psychiatric illness, depressed mood and a high number of psychopathological symptoms were also associated with in-patient railway suicide, whereas impulsivity and restlessness during the hospital stay were not. These findings need to be integrated into the practical clinical management of patients with serious mental disease.

Karoline Lukaschek, PhD, Jens Baumert, PhD, Institute of Epidemiology II, Helmholtz Zentrum München, German Research Centre for Environmental Health, Neuherberg; Marion Krawitz, MD, Natalia Erazo, PhD, Department for Psychosomatic Medicine and Psychotherapy, Hans Förstl, MD, Department for Psychiatry and Psychotherapy, Klinikum rechts der Isar, Technische Universität München, Munich; Karl-Heinz Ladwig, PhD, MD habil, Institute of Epidemiology II, Helmholtz Zentrum München, German Research Centre for Environmental Health, Neuherberg, and Department for Psychosomatic Medicine and Psychotherapy, Klinikum rechts der Isar, Technische Universität München, Munich, Germany

Correspondence: Professor K. H. Ladwig, Institute of Epidemiology II, Mental Health Unit, Helmholtz Zentrum München, German Research Centre for Environmental Health, Ingolstädter Landstr. 1, 85764 Neuherberg, Germany. Email: Iadwig@helmholtz-muenchen.de

First received 27 Sep 2013, final revision 2 Jun 2014, accepted 6 Jun 2014

\section{Acknowledgements}

The authors thank the following hospitals for their willingness to facilitate these research efforts: Zentrum für Psychiatrie Reichenau; Zentrum für Psychiatrie Emmendingen; Zentrum für Psychiatrie Winnenden; Isar-Amper-Klinikum, Klinikum München-Ost (former Bezirkskrankenhaus Haar): Klinikum Christophsbad Göppingen; Klinik für Psychiatrie und Psychotherapie Bad Schussenried. Personal thanks go to the members of clinical staff and management who supported our efforts, especially Dr Vogl (Christophsheim Göppingen), Professor Dr Schonauer and Dr Temme (Zentrum für Psychiatrie Reichenau), Dr Lutter and Dr Schieting (Zentrum für Psychiatrie Emmendingen), Dr Köhler (Zentrum für Psychiatrie Winnenden), Professor Dr Albus (Isar-Amper-Klinikum, forme Bezirkskrankenhaus Haar) and Dr Rath (Klinik für Psychiatrie und Psychotherapie Bad Schussenried). Finally, the authors thank Carla Dettweiler for her contribution in collectin the data and Alexander von Eisenhart Rothe for correcting the language of the manuscript.

\section{References}

1 Lloyd GG. Suicide in hospital: guidelines for prevention. J R Soc Med 1995; 88: 344P-6P.

2 Ballard ED, Pao M, Horowitz L, Lee LM, Henderson DK, Rosenstein DL. Aftermath of suicide in the hospital: institutional response. Psychosomatics 2008; 49: 461-9.

3 Dong JY, Ho TP, Kan CK. A case-control study of 92 cases of in-patient suicides. J Affect Disord 2005; 87: 91-9.

4 King EA, Baldwin DS, Sinclair JM, Baker NG, Campbell M, Thompson C. The Wessex Recent In-Patient Suicide Study, 1: case-control study of 234 recently discharged psychiatric patient suicides. Br J Psychiatry 2001; 178: 531-6.

5 Powell J, Geddes J, Deeks J, Goldacre M, Hawton K. Suicide in psychiatric hospital in-patients: risk factors and their predictive power. $\mathrm{Br} J$ Psychiatry 2000; 176: 266-72.

6 Hunt IM, Kapur N, Webb R, Robinson J, Burns J, Turnbull P, et al. Suicide in current psychiatric in-patients: a case-control study The National
Confidential Inquiry into Suicide and Homicide. Psychol Med 2007; 37 831-7.

7 Hunt IM, Bickley H, Windfuhr K, Shaw J, Appleby L, Kapur N. Suicide in recently admitted psychiatric in-patients: a case-control study. J Affect Disord 2013; 144: 123-8.

8 Roy A, Draper R. Suicide among psychiatric hospital in-patients. Psychol Med 1995; 25: 199-202.

9 Sharma V, Persad E, Kueneman K. A closer look at inpatient suicide. J Affect Disord 1998; 47: 123-9.

10 Large M, Smith G, Sharma S, Nielssen O, Singh SP. Systematic review and meta-analysis of the clinical factors associated with the suicide of psychiatric in-patients. Acta Psychiatr Scand 2011; 124: 18-29.

11 Roy A. Risk factors for suicide in psychiatric patients. Arch Gen Psychiatry 1982; 39: 1089-95.

12 Johansson LM, Johansson SE, Bergman B, Sundquist J. Suicide, ethnicity and psychiatric in-patient care: a case-control study. Arch Suicide Res 1997; 3: 253-69.

13 Qin $\mathrm{P}$, Nordentoft M. Suicide risk in relation to psychiatric hospitalization: evidence based on longitudinal registers. Arch Gen Psychiatry 2005; 62: 427-32.

14 Hunt IM, Windfuhr K, Swinson N, Shaw J, Appleby L, Kapur N, et al. Suicide amongst psychiatric in-patients who abscond from the ward: a national clinical survey. BMC Psychiatry 2010; 10: 14.

15 Bowers L, Banda T, Nijman $\mathrm{H}$. Suicide inside: a systematic review of inpatient suicides. J Nerv Ment Dis 2010; 198: 315-28.

16 Bowers L, Dack C, Gul N, Thomas B, James K. Learning from prevented suicide in psychiatric inpatient care: an analysis of data from the National Patient Safety Agency. Int J Nurs Stud 2011; 48: 1459-65.

17 Yeager K, Saveanu R, Roberts A, Reissland G, Mertz D, Cirpili A, et al. Measured response to identified suicide risk and violence: what you need to know about psychiatric patient safety. Brief Treat Crisis Interv 2005; 5: $121-41$.

18 Hunt IM, Swinson N, Palmer B, Turnbull P, Cooper J, While D, et al. Method of suicide in the mentally ill: a national clinical survey. Suicide Life Threat Behav 2010; 40: 22-34.

19 Ladwig KH, Ruf E, Baumert J, Erazo N. Prevention of metropolitan and railway suicide. In Oxford Textbook of Suicidology and Suicide Prevention (eds D Wasserman, C Wasserman): 589-94. OUP, 2009.

20 Erazo N, Baumert J, Ladwig KH. [Regional and local clusters of railway suicides]. Nervenarzt 2004; 75: 1099-106.

21 World Health Organization. International Statistical Classification of Diseases and Related Health Problems (ICD-10). WHO, 1992.

22 Homburger P: Hilfestellungen zur Einschätzung und Beurteilung suizidaler Patienten im stationären und ambulaten Betreuungssetting - Ein Projektbericht. Suizidprophylaxe 2003; 30: 13-22.

23 Hosmer D, Lemeshow S. Applied Logistic Regression. Wiley, 2000.

24 Breiman LFJ, Olshen A, Stone CJ. Classification and Regression Trees. Wadsworth, 1984.

25 Von Elm E, Altman DG, Egger M, Pocock SJ, Gotzsche PC, Vandenbroucke JP, et al. Strengthening the Reporting of Observational Studies in Epidemiology (STROBE) statement: guidelines for reporting observational studies. BMJ 2007; 335: 806-8.

26 Cassells C, Paterson B, Dowding D, Morrison R. Long- and short-term risk factors in the prediction of inpatient suicide: review of the literature. Crisis 2005; 26: 53-63.

27 Busch KA, Fawcett J, Jacobs DG. Clinical correlates of inpatient suicide. J Clin Psychiatry 2003; 64: 14-9.

28 Brezo J, Paris J, Turecki G. Personality traits as correlates of suicidal ideation, suicide attempts, and suicide completions: a systematic review. Acta Psychiatr Scand 2006; 113: 180-206.

29 Combs H. Psychiatric inpatient suicide: a literature review. Primary Psychiatry 2007; 14: 67-74.

30 Gusmao R, Quintao S, McDaid D, Arensman E, van Audenhove $\mathrm{CH}$, Coffey C, et al. Antidepressant utilization and suicide in Europe: an ecological multinational study. PLOS One 2013; 8: e66455.

31 Neuner T, Schmid R, Wolfersdorf M, Spiessl H. Predicting inpatient suicides and suicide attempts by using clinical routine data? Gen Hosp Psychiatry 2008; 30: 324-30.

32 Madsen T, Agerbo E, Mortensen PB, Nordentoft M. Predictors of psychiatric inpatient suicide: a national prospective register-based study. J Clin Psychiatry 2012; 73: 144-51.

33 Platt S. Unemployment and suicidal behaviour: a review of the literature. Soc Sci Med 1984; 19: 93-115. 
34 Chang SS, Stuckler D, Yip P, Gunnell D. Impact of 2008 global economic crisis on suicide: time trend study in 54 countries. BMJ 2013; 347: f5239.

35 Barr B, Taylor-Robinson D, Scott-Samuel A, McKee M, Stuckler D. Suicides associated with the 2008-10 economic recession in England: time trend analysis. BMJ 2012; 345: e5142.

36 Yur'yev A, Varnik A, Varnik $P$, Sisask M, Leppik L. Employment status influences suicide mortality in Europe. Int J Soc Psychiatry 2012; 58: 62-8.

37 Erlinghagen M. Self-perceived job insecurity and social context: a multi-leve analysis of 17 European countries. Eur Sociol Rev 2008; 24: 183-97.

38 Catalano R. Health, medical care, and economic crisis. N Engl J Med 2009; 360: 749-51.

39 Deisenhammer EA, DeCol C, Honeder $\mathrm{M}$, Hinterhuber $\mathrm{H}$, Fleischhacker WW. In-patient suicide in psychiatric hospitals. Acta Psychiatr Scand 2000; 102: 290-4.

40 Bhui $\mathrm{K}$, Chalangary J, Jones E. Railway Suicides in the UK: Risk Factors and Prevention Strategies. NHS England, 2013.

41 Debbaut K, Krysinska K, Andriessen K. Characteristics of suicide hotspots on the Belgian railway network. Int J Inj Contr Saf Promot 2013; Sep 10 (epub ahead of print).

42 Andriessen K, Krysinska K. Railway suicide in Belgium 1998-2009: incidence and prevention. Crisis 2012; 33: 39-45.

43 Lockley A, Williamson M, Robinson J, Cox G, Cheung Y, Grant L, et al. Preventing Suicide at Suicide Hotspots. Centre for Health Policy, Programs and Economics, University of Melbourne, 2012.

44 Symonds RL. Psychiatric aspects of railway fatalities. Psychol Med 1985; 15 : 609-21.

45 Van Houwelingen CA, Kerkhof AJ. Mental healthcare status and psychiatric diagnoses of train suicides. J Affect Disord 2008; 107: 281-4.

46 Krysinska K, De Leo D. Suicide on railway networks: epidemiology, risk factors and prevention. Aust N Z J Psychiatry 2008; 42: 763-71.

47 Baumert J, Erazo N, Ladwig KH. Ten-year incidence and time trends of railway suicides in Germany from 1991 to 2000. Eur J Public Health 2006; 16 173-8.
48 European Railway Agency. Railway Safety Performance in the European Union. ERA, 2011.

49 Law CK, Yip PS, Chan WS, Fu KW, Wong PW, Law YW. Evaluating the effectiveness of barrier installation for preventing railway suicides in Hong Kong. J Affect Disord 2009; 114: 254-62.

50 Matsubayashi T, Sawada $Y$, Ueda M. Does the installation of blue lights on train platforms prevent suicide? A before-and-after observational study from Japan. J Affect Disord 2013; 147: 385-8.

51 Mann JJ, Apter A, Bertolote J, Beautrais A, Currier D, Haas A, et al. Suicide prevention strategies: a systematic review. JAMA 2005; 294: 2064-74.

52 Isaac M, Elias B, Katz LY, Belik SL, Deane FP, Enns MW, et al. Gatekeeper training as a preventative intervention for suicide: a systematic review. Can J Psychiatry 2009; 54: 260-8.

53 Dinkel A, Baumert J, Erazo N, Ladwig KH. Jumping, lying, wandering: analysis of suicidal behaviour patterns in 1,004 suicidal acts on the German railway net. J Psychiatr Res 2011; 45: 121-5.

54 Lukaschek K, Baumert J, Ladwig KH. Behaviour patterns preceding a railway suicide: explorative study of German Federal Police officers' experiences. BMC Public Health 2011; 11: 620.

55 Lukaschek K, Baumert J, Erazo N, Ladwig KH. Stable time patterns of railway suicides in Germany: comparative analysis of 7,187 cases across two observation periods (1995-1998; 2005-2008). BMC Public Health 2014; 14: 124.

56 Meehan J, Kapur N, Hunt IM, Turnbull P, Robinson J, Bickley H, et al. Suicide in mental health in-patients and within 3 months of discharge: national clinical survey. Br J Psychiatry 2006; 188: 129-34.

57 Goldacre M, Seagroatt V, Hawton K. Suicide after discharge from psychiatric inpatient care. Lancet 1993; 342: 283-6.

58 Hunt IM, Kapur N, Webb R, Robinson J, Burns J, Shaw J, et al. Suicide in recently discharged psychiatric patients: a case-control study. Psychol Med 2009; 39: 443-9. 